\title{
Characterization and Fungicide Sensitivity of Colletotrichum spp. from Different Hosts in Shandong, China
}

Lifei He, Xiaoxu Li, Yangyang Gao, Beixing Li, Wei Mu, and Feng Liu, ${ }^{\dagger}$ Shandong Provincial Key Laboratory for Biology of Vegetable Diseases and Insect Pests, College of Plant Protection, Shandong Agricultural University, Tai'an, Shandong 271018, P. R. China

\begin{abstract}
Anthracnose, caused by Colletotrichum species, can severely infect the fruits and leaves of more than 30 plants and thus results in great yield and quality losses. To identify the major Colletotrichum species infecting walnut fruits, strawberry leaves, grape fruits, and tea leaves in Shandong Province, China, 101 strains were collected and isolated. The morphological characteristics of all isolates were observed, and multilocus phylogenetic analyses (ITS, GAPDH, ACT, TUB2, CAL, CHS-1, and HIS3) were conducted on the representative isolates. The strains were identified as five Colletotrichum species, namely, C. gloeosporioides sensu stricto, C. fructicola, C. camelliae, C. acutatum sensu stricto, and C. viniferum. Among them, $C$. viniferum was reported for the first time from walnut fruits and strawberry leaves in Shandong Province, China. Corresponding

leaves or fruits were used as a model to clarify the pathogenicity of these isolates. The results showed that $C$. fructicola obtained from strawberry leaves was more aggressive than $C$. viniferum. All of the isolates obtained from various hosts were highly sensitive to pyraclostrobin, difenoconazole, fludioxonil, tebuconazole, pyrisoxazole, and tetramycin in terms of mycelial growth inhibition ( $\mathrm{EC}_{50}$ values of 0.07 to $1.63 \mathrm{mg} / \mathrm{liter}$ ). The fastest mycelial growth was observed in the temperature range of $25-28^{\circ} \mathrm{C}$ for all isolates. In addition, anthracnose symptoms occur frequently under these conditions. Overall, this study can improve the understanding of $\mathrm{Col}$ letotrichum species causing anthracnose in walnut fruits, strawberry leaves, grape fruits, and tea leaves and can provide a solid foundation for the effective control of this disease in different hosts.
\end{abstract}

Colletotrichum is one of the most disastrous plant pathogens worldwide (Cannon et al. 2012; Hyde et al. 2014; Nilsson et al. 2014; Yan et al. 2015), occurring mainly in a wide range of crops in tropical and subtropical areas (Hyde et al. 2009a, b, 2014). Anthracnose has also become increasingly prevalent in Shandong Province. It has lately become the most economically subversive disease, especially causing rot of walnut fruits and grape fruits, and leaf scorch disease of strawberries and tea plants.

Walnut is an important nut and woody oil tree species worldwide. It has important economic value and medicinal value (Mcgranahan et al. 1988). The U.S. Food and Drug Administration (FDA) made a milestone decision to give walnut a claim as a health product (Zhu et al. 2014). A previous study showed that the incidence of anthracnose was $90 \%$ and that the diseased fruit rate was above $30 \%$ in walnut production areas in Shandong Province (Liu 2013). Strawberries are cultivated in temperate zones and certain subtropical areas (Lin et al. 2016). Currently, strawberries are a major crop cultivated in China, and China has become the largest producer and exporter of strawberries in the world (Xie et al. 2010). Anthracnose can occur throughout the production cycle, especially in the seedling and transplanting periods of the strawberry plants (Smith 2008). Grapes are one of the most diffusely cultivated fruit worldwide, whether for wine production or fruit consumption (Hong et al. 2008). During the ripening process of grape fruits, heavy rainfall and warm summer conditions in most of the grape growing areas in China have resulted in the loss of production due to anthracnose ( $\mathrm{Lu} 2005)$. The ripe rot of grapes caused by Colletotrichum spp. has become a serious disease in most grape growing areas, particularly in Shandong, China. The tea plant, a popular nonalcoholic beverage crop, is cultivated in tropical and subtropical areas. China, which was one of the first countries to begin cultivating tea trees, plants the largest variety of tea plants over the widest area in the world (Chen and Yang 2011). In recent years,

${ }^{\dagger}$ Corresponding author: F. Liu; E-mail: fliu@sdau.edu.cn

Funding: This work was supported by a grant from the National Key R\&D Program of China (2016YFD0200501).

Accepted for publication 24 June 2018

() 2019 The American Phytopathological Society plantation acreage and total output have experienced rapid growth in China. Because of the high planting density, anthracnose frequently occurs, causing severe damage such as fruit necrosis, stem rot, leaf scorch, and defoliation (Hyde et al. 2009a; Qu et al. 2011), ultimately leading to serious losses in yield (Guo et al. 2014).

Due to overlapping characteristics, morphological classification of species is arduous in this genus. Combining morphological and molecular tools can provide a robust and precise identification of fungi at the species level. At present, the majority of studies conducted regarding this disease principally focus on morphology combined with multilocus phylogenetic analysis (Damm et al. 2012a; Diao et al. 2017; Silva et al. 2016; Weir et al. 2012), which provides a more reliable resolution (Cai et al. 2009; Hyde et al. 2014). The sensitivities to fungicides of the species $C$. siamense, $C$. fructicola, $C$. fioriniae, C. theobromicola, C. acutatum sensu stricto, and C. gloeosporioides s.s. are well known to differ (Freeman et al. 1998; Munir et al. 2016; Peres et al. 2004; Valero et al. 2010). Recently, Hu et al. (2015) reported a substantial difference in the fungicide sensitivity of $C$. siamense and $C$. fructicola, two species belonging to the $C$. gloeosporioides species complex that cause anthracnose on blueberry and peach plants. No complete research is found in the current reference literature regarding anthracnose on walnuts, grapes, strawberries, and tea plants. Therefore, it is imperative to identify phylogenetic species within Colletotrichum complexes and to clarify their pathogenicity and fungicide sensitivity to enhance the management of anthracnose.

The objectives of this research are as follows: (1) to identify the species of Colletotrichum causing anthracnose on different hosts by morphological characteristics and multilocus phylogenetic analyses, (2) to determine the pathogenicity and growth characteristics of different Colletotrichum species, and (3) to determine the inhibitory effect of fungicides against mycelial growth of different Colletotrichum species.

\section{Materials and Methods}

Collection and isolates. In 2016, a total of 101 Colletotrichum spp. isolates were collected from different plants in Jinan, Tai'an, and Qindao of Shandong Province, China. Isolates were collected from commercial orchards where the anthracnose was serious and yield losses were heavy. Among them, the numbers of strains collected from walnut fruits (Liuzhong village, Jinan, China, 117.07 E, $36.69 \mathrm{~N}$ ), strawberry leaves (High-tech district, Qindao, China, 
120.33 E, $36.07 \mathrm{~N}$ ), grape fruits (Daiyue district, Tai'an, China, 117.13 E, $36.18 \mathrm{~N}$ ), and tea leaves (Feicheng, Tai'an, China, $116.76 \mathrm{E}, 36.24 \mathrm{~N}$ ) were $17,21,38$, and 25 , respectively. Small pieces of disease lesion were disinfested with $70 \%$ ethanol for 30 $\mathrm{s}$, washed three times with distilled sterile water, and dried with sterilized paper. Tissues were plated on potato dextrose agar (PDA) medium and incubated at $25^{\circ} \mathrm{C}$ for $24 \mathrm{~h}$ in the dark for 2 days. Fungal colonies with the typical characteristics of Colletotrichum spp. were transferred to new plates containing PDA medium. Isolates were preserved on PDA slants at $4^{\circ} \mathrm{C}$ in the dark.

Morphological characterization. Mycelial plugs $(8 \mathrm{~mm})$ were transferred from the edge of actively growing cultures to fresh PDA plates. The plates were kept at $25^{\circ} \mathrm{C}$ in the dark. The morphological characteristics of each isolate, including colony, conidial, and appressorial characteristics, were evaluated. Colony characteristics were determined after incubation for 8 days. Conidia morphology and production of appressoria were observed on water agar plates (WA; $20 \mathrm{~g}$ dextrose, $10 \mathrm{~g}$ agar, 1 liter distilled water) after 3 days of incubation by slide culture technology (Johnston and Jones 1997). The lengths and widths of 50 randomly chosen conidia and appressoria were then measured (Du et al. 2005). Isolates obtained from each host were divided into one to two morphological groups based on colony color and spore and appressoria shape. In total, 24 model isolates that contained all morphotypes and were collected from different host plants were selected for further study. Five to seven randomly selected isolates from each host were selected.

Isolation of fungal DNA. Mycelia were collected from cultures grown on PDA and ground after lyophilization. They were then macerated with Buffer FG1 (Omega Biotech) in 1.5-ml centrifuge tubes. Fungal genomic DNA was extracted with an E.Z.N.A. Fungal DNA Mini Kit (Omega Biotech) according to the manufacturers' instructions.

Molecular characterization: Multigene amplification and DNA sequencing. PCR amplification was performed for the following loci: the internal transcribed spacer regions (ITS), glyceraldehyde3-phosphate dehydrogenase $(G A P D H)$, actin $(A C T), \beta$-tubulin 2 (TUB2), calmodulin $(C A L)$, chitin synthase $1(C H S-1)$, and histone 3 (HIS3). The primers used in this study are shown in Table 1. PCR was performed in an EasyCycler Gradient 96-well Thermal cycler (Biometra, Goettingen, Germany) in a total volume of $25 \mu$ l. The $25-\mu$ l reaction mixture comprised $12.5 \mu \mathrm{l} 2 \times$ Taq Master Mix (Novoprotein Scientific Inc.), $0.5 \mu \mathrm{l}$ of each primer $(20 \mu \mathrm{M}), 1 \mu \mathrm{l}$ of template DNA, and $10.5 \mu \mathrm{l}$ of $\mathrm{ddH}_{2} \mathrm{O}$. PCR amplification protocols were performed as described by Damm et al. (2012a, b) and Silva et al. (2012), but the annealing temperatures were $54.9^{\circ} \mathrm{C}$ for ITS and $A C T$; $56^{\circ} \mathrm{C}$ for $C A L, C H S-1$, and $H I S 3$; and $61.4^{\circ} \mathrm{C}$ for $G A P D H$ and $T U B 2$. The PCR products were electrophoresed on $1 \%$ agarose (HyAgarose LE Agarose, HydraGene Co., Ltd.) gel in 1.0× TAE (Tris-acetic acid-EDTA) buffer stained with GelRed (Biotium, USA) and visualized in a UV-transilluminator. A DNA gel Recovery Kit (BioTeke) was used for rubber recovery. The recovered products were sequenced by Biosune Biotechnology (Shanghai) Co., Ltd.
Sequence alignment and phylogenetic analysis. The DNA sequences generated with forward and reverse primers were used to acquire consistent sequences using the BioNumerics version 5.1 software (Damm et al. 2012a), and their accession numbers are listed in Table 2. Sequences with high similarities were chosen and used in the analyses. A BLAST sequence identity search (Weir et al. 2012) was carried out to compare data from our isolate with those of other fungi deposited in the GenBank database and subsequently aligned using MUSCLE version 6 software (Edgar 2004). The alignments were edited manually using MEGA version 6 software (Tamura et al. 2013). Maximum likelihood (ML) and neighbor-joining (NJ) analyses combined with the combined datasets were analyzed using MEGA version 6 software. Phylogenetic trees were generated using the heuristic search option with TBR branch swapping and 1,000 random sequence additions. Maxtrees were unlimited, with branches of zero length collapsed, and all multiple parsimonious trees were saved. Clade stability was assessed using a bootstrap analysis with 1,000 replicates, each with 10 replicates of random stepwise addition of taxa.

Pathogenicity assay. Representative materials (walnut fruits, strawberry leaves, grape fruits, and tea leaves) were used as the test material in the pathogenicity tests. Pathogenicity tests were conducted using the representative strains of each species. Isolates of each species were inoculated on detached leaves or fruits. The tested leaves or fruits were disinfected with $70 \%$ ethanol for $60 \mathrm{~s}$, rinsed three times with sterile distilled water, and then air-dried on disinfectant paper towels at room temperature. Conidial suspensions were obtained from 7-day-old colonies by adding 5-10 $\mathrm{ml}$ of sterile distilled water into each culture, scraping the mycelia from plates, and filtering with two layers of gauze. The concentration of the conidia suspension was determined using a hemocytometer and adjusted to a final concentration of $1 \times 10^{5} \mathrm{ml}^{-1}$. Leaves or fruits were wounded with a sterile dissecting needle that had been modified to produce a puncture of $0.5 \mathrm{~mm}$ in depth (Biggs and Miller 2001; Velho et al. 2015). The wounded leaves or fruits were placed in sterilized plastic containers and then were inoculated by pipetting $10 \mu \mathrm{l}$ of conidial suspension onto each wound. After inoculation, the leaves or fruits were incubated in a growth chamber with $85 \%$ relative humidity (photoperiod of $12-12 \mathrm{~h} \mathrm{light/dark)} \mathrm{at} 25^{\circ} \mathrm{C}$ for 12 days, and then the lesion diameters were measured. Eight uninoculated leaves or fruits were used as the control. Eight leaves or fruits were tested for each isolate, and the experiment was repeated three times. To compare the differences in pathogenicity of each isolate, variance analyses were performed using the least significant difference (LSD) test in SPSS software (Version 13.0 for Windows) $(P=0.05)$.

Fungicide sensitivity assays on mycelial growth. Technical grade pyraclostrobin (95\% active ingredient [a.i.]; Hubei Kang Bao Tai Fine-Chemical Co., Ltd., Hubei, China), difenoconazole (95\% a.i.; Rainbow Chemical Co., Ltd., Shandong, China), fludioxonil (95\% a.i.; Rainbow Chemical Co., Ltd., Shandong, China), tebuconazole (97\% a.i.; Rainbow Chemical Co., Ltd., Shandong, China),

Table 1. Primers used for PCR and sequencing in this study

\begin{tabular}{|c|c|c|c|c|c|}
\hline Gene & Product name & Primer & Direction & Sequence $\left(5^{\prime}-3^{\prime}\right)$ & Reference \\
\hline \multirow[t]{2}{*}{ ITS } & Internal transcribed spacer & ITS1 & Forward & CTTGGTCATTTAGAGGAAGTAA & Gardes and Bruns 1993 \\
\hline & & ITS4 & Reverse & TCCTCCGCTTATTGATATGC & White et al. 1990 \\
\hline \multirow[t]{2}{*}{ GAPDH } & Glyceraldehyde-3-phosphate dehydrogenase & GDF1 & Forward & GCCGTCAACGACCCCTTCATTGA & Guerber et al. 2003 \\
\hline & & GDR1 & Reverse & GGGTGGAGTCGTACTTGAGCATGT & Guerber et al. 2003 \\
\hline \multirow[t]{2}{*}{$\mathrm{ACT}$} & Actin & ACT-512F & Forward & ATGTGCAAGGCCGGTTTCGC & Carbone and Kohn 1999 \\
\hline & & ACT-783R & Reverse & TACGAGTCCTTCTGGCCCAT & Carbone and Kohn 1999 \\
\hline \multirow[t]{2}{*}{ TUB2 } & $\beta$-tubulin 2 & $\mathrm{~T} 1$ & Forward & AACATGCGTGAGATTGTAAGT & O’Donnell and Cigelnik 1997 \\
\hline & & $\mathrm{Bt}-2 \mathrm{~b}$ & Reverse & ACCCTCAGTGTAGTGACCCTTGGC & Glass and Donaldson 1995 \\
\hline \multirow[t]{2}{*}{ CAL } & Calmodulin & CL1A & Forward & GATCAAGGAGGCCTTCTC & O’Donnell et al. 2000 \\
\hline & & CL2A & Reverse & TTTTTGCATCATGAGTTGGAC & O'Donnell et al. 2000 \\
\hline \multirow[t]{2}{*}{ CHS-1 } & Chitin synthase 1 & CHS-79F & Forward & TGGGGCAAGGATGCTTGGAAGAAG & Carbone and Kohn 1999 \\
\hline & & CHS-354R & Reverse & TGGAAGAACCATCTGTGAGAGTTG & Carbone and Kohn 1999 \\
\hline \multirow[t]{2}{*}{ HIS3 } & Histone 3 & CYLH3F & Forward & AGGTCCACTGGTGGCAAG & Crous et al. 2004 \\
\hline & & CYLH3R & Reverse & AGCTGGATGTCCTTGGACTG & Crous et al. 2004 \\
\hline
\end{tabular}


pyrisoxazole (25\% EC; Shenyang Sciencreat Chemical Co., Ltd., Liaoning, China), and tetramycin (15\% a.i.; Liaoning Wkioc Bioengineering Co., Ltd., Liaoning, China) were used in the in vitro sensitivity assay. Stock solutions of pyraclostrobin, difenoconazole, and tetramycin were used in the tests by dissolving them in acetone to yield the concentration of $10,000 \mathrm{mg} / \mathrm{liter}$, while fludioxonil and tebuconazole were dissolved in methanol to obtain a concentration of $10,000 \mathrm{mg} / \mathrm{liter}$. Stock solutions were stored at $4^{\circ} \mathrm{C}$ in the dark until use. The stock solutions were diluted to a series of concentrations and were added to cooled molten potato dextrose agar (PDA) (approximately $50^{\circ} \mathrm{C}$; approximately $15 \mathrm{ml}$ per plate) after autoclaving. Salicylhydroxamic acid (SHAM) was added to the PDA amended with pyraclostrobin to yield a final concentration of $100 \mathrm{mg} / \mathrm{liter}$. SHAM was used to inhibit the alternative oxidase respiration pathway. PDA plates with $0.2 \%$ organic solvent or SHAM were used as the control. Mycelial plugs ( $8 \mathrm{~mm}$ ) cut from the active colony margins were placed upside down on PDA plates. After incubation for
5 days at $25^{\circ} \mathrm{C}$ in the dark, the diameter of each colony was measured in two perpendicular directions, and the mean diameter was obtained by subtracting the original diameter of the inoculation plugs. The experiment was repeated twice with three replicates. The percent inhibition was calculated as [(growth of the control - growth of the experimental)/growth of the control] $\times 100$. The $\mathrm{EC}_{50}$ values were calculated by performing a regression of the probit-transformed percent inhibition against the $\log _{10}$ fungicide concentrations, and the correlation coefficients $(r)$ were determined using the statistical algorithms of SPSS software (Version 13.0 for Windows).

Temperature effects on growth rate. To evaluate the effect of temperature on the growth of representative Colletotrichum spp. collected from different hosts, mycelial plugs $(8 \mathrm{~mm})$ were cut from the active colony margins on PDA and transferred onto the center of 9 -cm plates containing approximately $15 \mathrm{ml}$ of PDA. The cultures were separately incubated at five different temperatures $(21,23,25,28$, and $30^{\circ} \mathrm{C}$ ) in the dark for 8 days. The mean colony diameter (minus

Table 2. Strains of Colletotrichum spp. isolated from four hosts studied. Details are provided about host and locality, and GenBank accession numbers of the sequences generated.

\begin{tabular}{|c|c|c|c|c|c|c|c|c|c|c|}
\hline \multirow[b]{2}{*}{ Species } & \multirow[b]{2}{*}{ Culture } & \multirow[b]{2}{*}{ Host } & \multirow[b]{2}{*}{ Locality } & \multicolumn{7}{|c|}{ GenBank accession number } \\
\hline & & & & ITS & GAPDH & ACT & TUB2 & CAL & CHS & HIS3 \\
\hline \multirow{6}{*}{$\begin{array}{l}\text { C. acutatum sensu } \\
\text { stricto }\end{array}$} & CBS $112996^{a}$ & Carica papaya & Australia & JQ005776 & JQ948677 & JQ005839 & JQ005860 & - & JQ005797 & JQ005818 \\
\hline & CBS 144.29 & Capsicum annuum & Sri Lanka & JQ948401 & JQ948732 & JQ949722 & JQ950052 & - & JQ949062 & JQ949392 \\
\hline & CBS 110735 & Pinus radiata & South Africa & JQ948354 & JQ948685 & JQ949675 & JQ950005 & - & JQ949015 & JQ949345 \\
\hline & CBS 127539 & Aspalathus linearis & South Africa & JQ948377 & JQ948708 & JQ949698 & JQ950028 & - & JQ949038 & JQ949368 \\
\hline & HTTJ1 & Juglans regia $\mathrm{L}$. & China & MG561705 & MG561689 & MG561655 & MG561717 & MG561665 & MG561677 & - \\
\hline & HTTJ3 & Juglans regia $\mathrm{L}$. & China & MH092012 & MH113902 & MH113867 & MH113914 & MH113878 & MH113890 & - \\
\hline \multirow[t]{8}{*}{ C. camelliae } & JS1A7 & Camellia sinensis & China & KU251586 & KU252040 & KU251667 & KU252192 & KU251828 & KU251934 & - \\
\hline & JS1A46 & Camellia sinensis & China & KU251585 & KU252039 & KU251666 & KU252191 & KU251827 & KU251933 & - \\
\hline & LC1363 & Camellia sinensis & China & KJ955080 & KJ954781 & KJ954362 & KJ955229 & KJ954633 & - & - \\
\hline & CSTJ2 & Camellia sinensis & China & MG561702 & MG561686 & MG561652 & MG561714 & MG561662 & MG561674 & - \\
\hline & CSTJ8 & Camellia sinensis & China & MG561703 & MG561687 & MG561653 & MG561715 & MG561663 & MG561675 & MG561697 \\
\hline & CSTJ13 & Camellia sinensis & China & MG561704 & MG561688 & MG561654 & MG561716 & MG561664 & MG561676 & - \\
\hline & CSTJ20 & Camellia sinensis & China & MH092010 & MH113900 & MH113865 & MH113912 & MH113876 & MH113888 & - \\
\hline & CSTJ23 & Camellia sinensis & China & МH092011 & MH113901 & MH113866 & MH113913 & MH113877 & MH113889 & - \\
\hline \multirow[t]{8}{*}{ C. fructicola } & $\mathrm{C} 1316.21$ & Tetragastris panamensis & Panama & JX010173 & JX010032 & JX009581 & JX010409 & JX009674 & JX009874 & - \\
\hline & CAUG21 & Capsicum sp. & China & KP145434 & KP145406 & KP145322 & KP145462 & KP145350 & KP145378 & - \\
\hline & CCON5 & Gossypium hirsutum L. & China & KJ781342 & KJ781334 & KJ781309 & KJ781350 & KJ781317 & KJ781326 & - \\
\hline & LF647 & Camellia sinensis & China & KJ955190 & KJ954891 & KJ954463 & KJ955337 & KJ954741 & - & - \\
\hline & CMTJ1 & Fragaria ananassa & China & MG561700 & MG561684 & MG561650 & MG561712 & - & MG561672 & MG561696 \\
\hline & CMTJ7 & Fragaria ananassa & China & MH092005 & MH113895 & MH113860 & MH113907 & - & MH113883 & MH113872 \\
\hline & CMTJ9 & Fragaria ananassa & China & MH092006 & MH113896 & MH113861 & MH113908 & - & MH113884 & MH113873 \\
\hline & CMTJ18 & Fragaria ananassa & China & MH092008 & MH113898 & MH113863 & MH113910 & - & MH113886 & MH113874 \\
\hline \multirow{16}{*}{$\begin{array}{l}\text { C. gloeosporioides } \\
\text { sensu stricto }\end{array}$} & CCOW3 & Gossypium hirsutum L. & China & KJ781337 & KJ781329 & KJ781304 & KJ781345 & KJ781312 & KJ781321 & - \\
\hline & CDLG4 & Hemerocallis fulva & China & JQ400009 & JQ400016 & JQ399995 & JQ400023 & - & JQ400002 & - \\
\hline & DNCL022 & Syzygium samarangense & Thailand & KF242097 & KF242159 & KF157804 & KF254853 & KF254849 & - & - \\
\hline & GZAAS5.09516 & Citrus reticulata & China & JQ247627 & JQ247604 & JQ247652 & JQ247639 & JQ247593 & - & - \\
\hline & IMI 356878 & Citrus sinensis & Italy & JX010152 & JX010056 & JX009531 & JX010445 & JX009731 & JX009818 & - \\
\hline & LJTJ13 & Capsicum sp. & China & KP748204 & KP823783 & KP823751 & KP823863 & KP823821 & - & - \\
\hline & LJTJ87 & Capsicum sp. & China & KT936448 & KP943521 & KT936437 & - & KT936431 & - & - \\
\hline & LN-48 & Juglans regia & China & KY302640 & KY302636 & KY302628 & - & - & KY302632 & - \\
\hline & sxwgzg14 & Proteaceae & China & KC293560 & KC293720 & KC293600 & KC293640 & KC293680 & - & - \\
\hline & PTTJ1 & Vitis spp. & China & MG561707 & MG561691 & MG561657 & MG561719 & MG561667 & MG561679 & - \\
\hline & PTTJ7 & Vitis spp. & China & MG561708 & MG561692 & MG561658 & MG561720 & MG561668 & MG561680 & - \\
\hline & PTTJ11 & Vitis spp. & China & MG561709 & MG561693 & MG561659 & MG561721 & MG561669 & MG561681 & - \\
\hline & PTTJ14 & Vitis spp. & China & MG561710 & MG561694 & MG561660 & MG561722 & MG561670 & MG561682 & MG561699 \\
\hline & PTTJ22 & Vitis spp. & China & MG561711 & MG561695 & MG561661 & MG561723 & MG561671 & MG561683 & - \\
\hline & PTTJ24 & Vitis spp. & China & MH092015 & MH113905 & MH113870 & MH113917 & MH113881 & MH113893 & - \\
\hline & PTTJ38 & Vitis spp. & China & MH092016 & MH113906 & MH113871 & MH113918 & MH113882 & MH113894 & - \\
\hline C. guajavae & IMI 350839 & Psidium guajava & India & JQ948270 & JQ948600 & JQ949591 & JQ949921 & - & JQ948931 & JQ949261 \\
\hline \multirow[t]{9}{*}{ C. viniferum } & B27 & Vitis vinifera & China & KF156852 & KF377483 & KF377520 & KF288971 & - & KF288996 & - \\
\hline & $\mathrm{C} 1-3$ & Vitis vinifera & China & KF156840 & KF377469 & KF377506 & KF288965 & - & KF288982 & - \\
\hline & D1-1 & Vitis vinifera & China & KF156842 & KF377471 & KF377508 & KF288966 & - & KF288984 & - \\
\hline & CMTJ4 & Fragaria ananassa & China & MG561701 & MG561685 & MG561651 & MG561713 & - & MG561673 & - \\
\hline & CMTJ13 & Fragaria ananassa & China & МH092007 & MH113897 & MH113862 & MH113909 & - & MH113885 & - \\
\hline & CMTJ21 & Fragaria ananassa & China & МH092009 & MH113899 & MH113864 & MH113911 & - & MH113887 & - \\
\hline & HTTJ6 & Juglans regia $\mathbf{L}$. & China & МH092013 & MH113903 & MH113868 & MH113915 & MH113879 & MH113891 & MH113875 \\
\hline & HTTJ12 & Juglans regia L. & China & MH092014 & MH113904 & MH113869 & MH113916 & MH113880 & MH113892 & - \\
\hline & HTTJ15 & Juglans regia $\mathbf{L}$. & China & MG561706 & MG561690 & MG561656 & MG561718 & MG561666 & MG561678 & MG561698 \\
\hline
\end{tabular}

${ }^{\text {a }}$ Ex-type culture. Strains/sequences studied in this paper are in bold font. 
the original diameter of the inoculation plug) was measured. The experiment was repeated twice with three replicates. The growth rate was computed as the mean daily growth rate.

\section{Results}

Morphological characterization. The 101 isolates were divided into six morphological types based on colony morphology and color, spore and appressoria shape, and mycelial morphology. Two groups came from walnut fruits, two groups from strawberry leaves, one group from grape fruits, and the other group from tea leaves.

Isolates collected from walnut fruits had light gray aerial mycelium and belonged to group 1 of $C$. viniferum (Fig. 1A1). The reverse side of the colony was pale olivaceous gray with a whitish margin (Fig. 1B1). The vegetative hyphae were hyaline, smooth-walled, and septate (Fig. 1C1). Conidia were hyaline, smooth-walled or minutely verruculose, aseptate, guttulate, cylindrical to clavate, with both
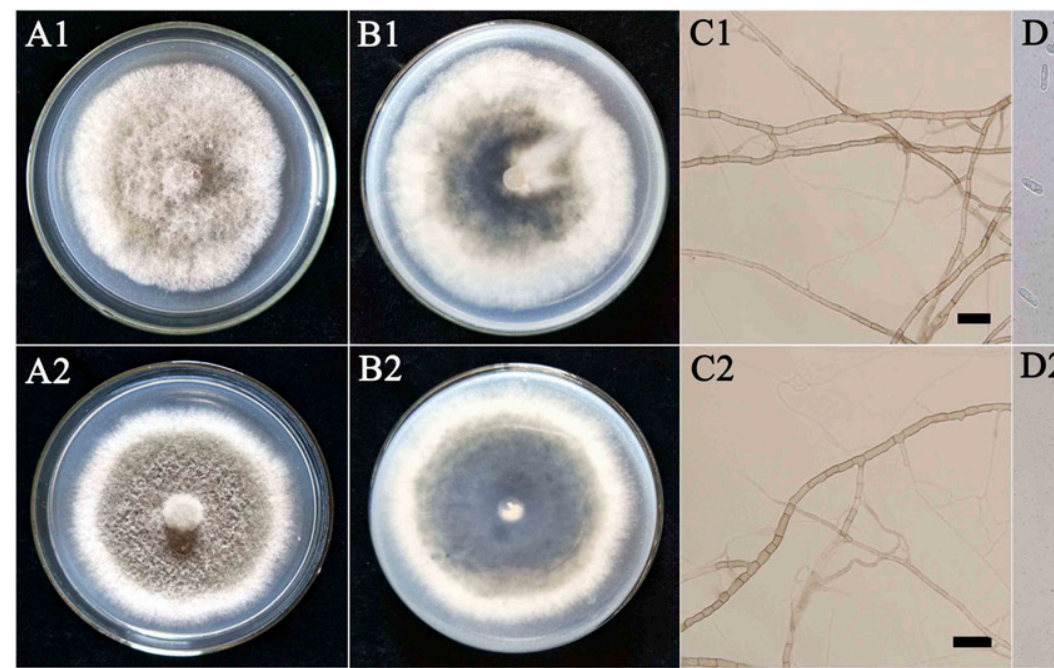

D1

E1

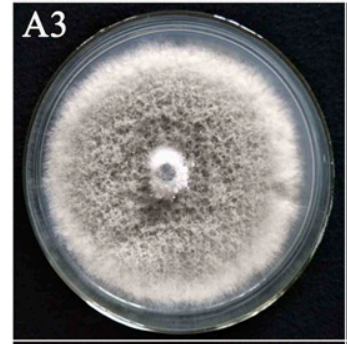

B3

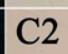

D2
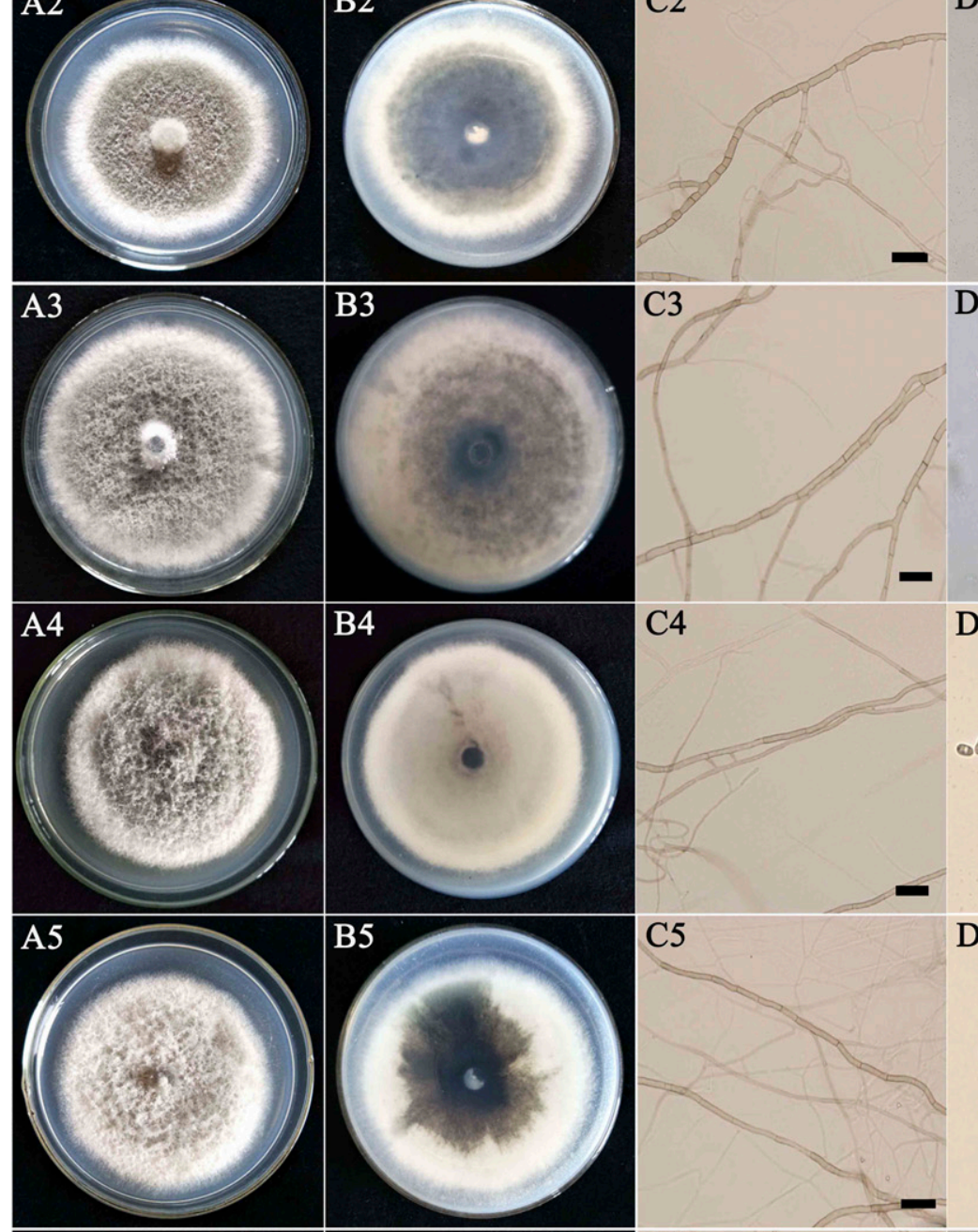

B5
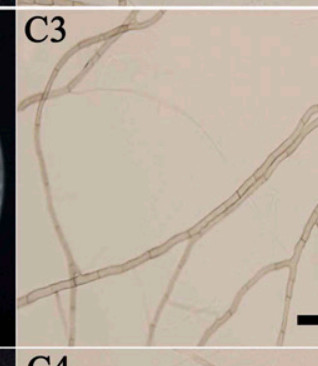

C4
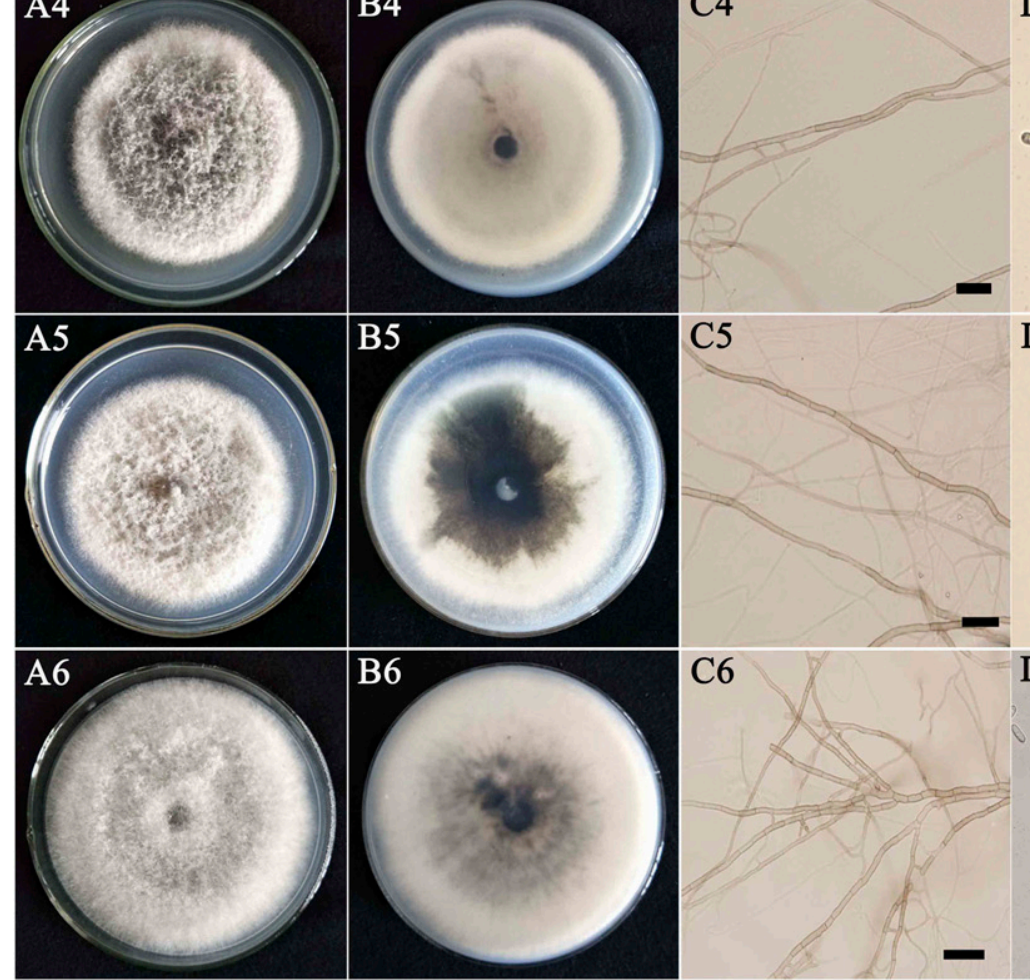

D5
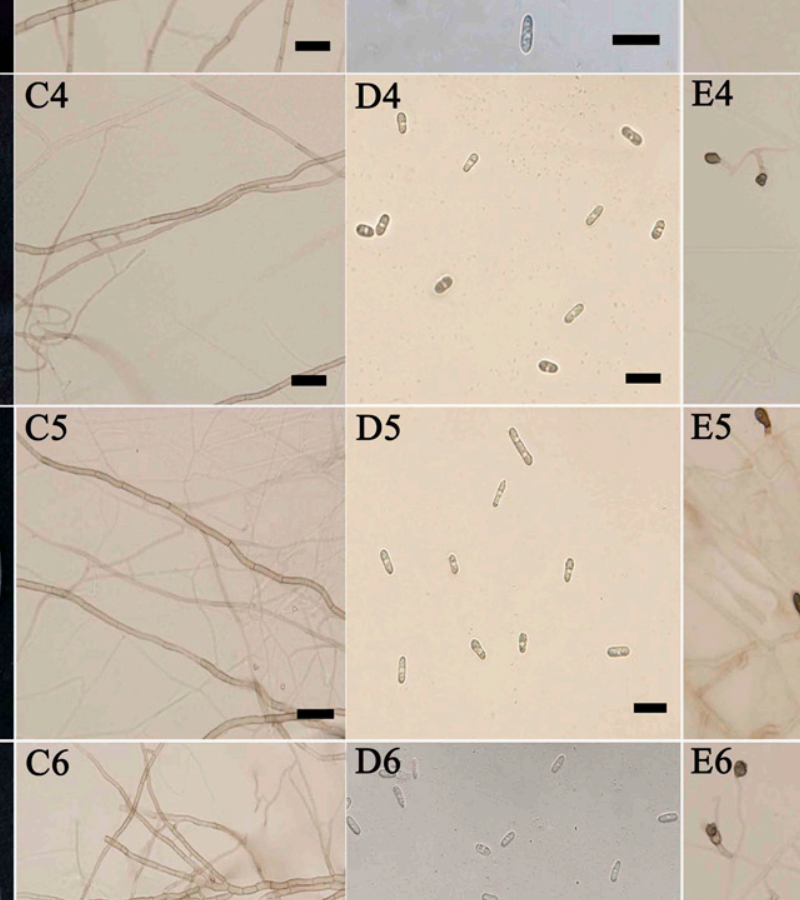

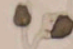
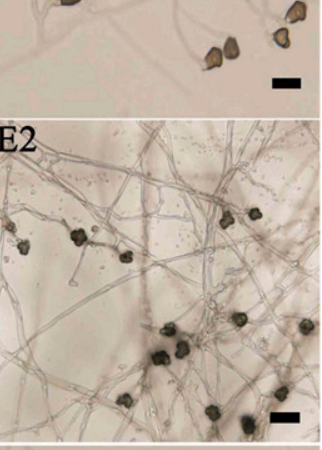

E3
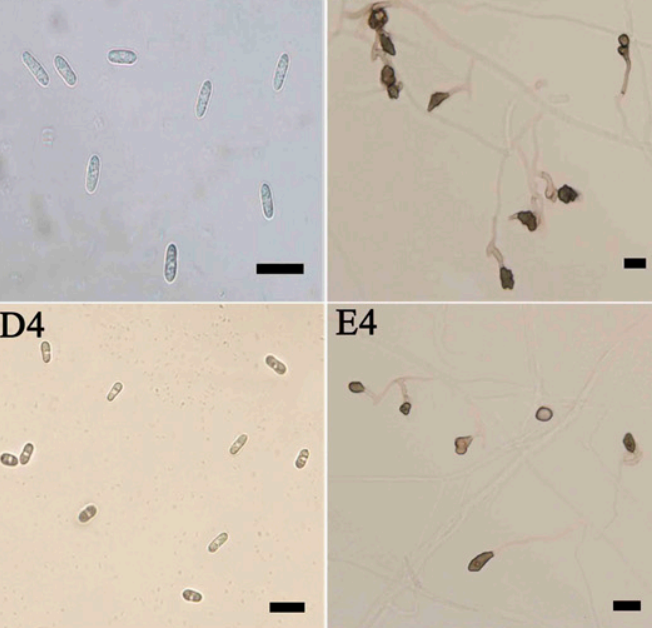

E5

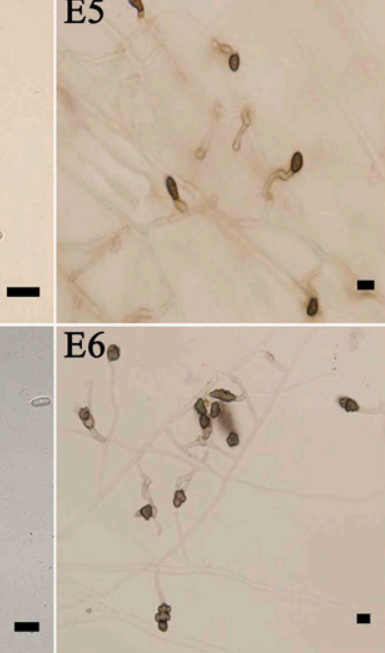

Fig. 1. Cultural characteristics and morphology of Colletotrichum spp. isolated from different hosts in China. A1-E1, group 1; A2-E2, group 2; A3-E3, group 3; A4-E4, group 4; A5E5, group 5; A6-E6, group 6. A, upper of colony on PDA; B, reverse of colony on PDA; C, micrographs of mycelium; $D$, micrographs of conidia; $E$, micrographs of appressoria. Scale bars $=20 \mu \mathrm{m}$. 
ends rounded (Fig. 1D1). Appressoria were single, medium to dark brown, aseptate, and ovoid (Fig. 1E1).

Colonies of isolates collected from walnut fruits belonging to group 2 of $C$. acutatum s.s. were charcoal gray and had a flat center with white aerial hyphae at the margin (Fig. 1A2). The reverse side of the colony was densely arranged with olivaceous gray in the middle area (Fig. 1B2). Mycelia were smooth-walled, septate, and branched, and the partitive membranes of the hyphae were shorter than in group 1 (Fig. 1C2). Conidia were principally straight, with a rounded and a pointed end (Fig. 1D2). Appressoria were medium brown, single or in small dense clusters, roughly round to irregular in outline, and crenate at the margins (Fig. 1E2).

Colonies of the group 3 isolates which corresponded to $C$. fructicola from strawberry leaves produced an abundance of light gray aerial mycelium with white margins (Fig. 1A3), and the reverse side was pale olivaceous gray with concentric rings (Fig. 1B3). Mycelia were medium to dark brown, septate, and smooth-walled (Fig. 1C3). Conidia were cylindrical or clavate, with both ends rounded or one end acute (Fig. 1D3). The appressoria were medium to dark brown and formed singly, with ellipsoidal to irregular outlines (Fig. 1E3).

The isolates from strawberry leaves of group 4 corresponded to $C$. viniferum and had gray, dense, cottony mycelia on the upper surface (Fig. 1A4), while the color of the mycelia on the reverse side were white (Fig. 1B4). In addition, mycelia were connected with tiny mycelia that were dark brown and septate (Fig. 1C4). Conidia were cylindrical to clavate, straight, with each apex rounded, containing one oil globule (Fig. 1D4). Appressoria were single, subglobose to cylindrical, or clavate with a medium to dark brown color (Fig. 1E4).

The group 5 isolates obtained from grape fruits of $C$. gloeosporioides s.s. exhibited dense light gray aerial mycelium (Fig. 1A5), and the reverse side seemed olivaceous to black, radial, with white margins (Fig. 1B5). Mycelia were medium to dark brown, smoothwalled, and septate (Fig. 1C5). Conidia were cylindrical to clavate, with one to two oil globules (Fig. 1D5). Appressoria were single, ovoid or cylindrical, smooth-walled, and seemed medium to dark brown (Fig. 1E5).

The mycelia of the isolates from tea leaves in group 6 corresponded to $C$. camelliae and were white, fluffy, and cottony, with abundant aerial mycelia (Fig. 1A6). The reverse side was white to gray, with melanin in the center of the bottom (Fig. 1B6). Mycelia were light brown, smooth-walled, septate, and mostly branched (Fig. 1C6). Conidia were hyaline, ovoid to cylindrical, and guttulate (Fig. 1D6). Appressoria were multicell, puce, and mostly irregular in outline. They were always lobed, crenate, and catenate (Fig. 1E6).

The sizes of conidia and appressoria of the 24 representative isolates were determined and compared (Table 3). Isolates collected from tea leaves had the longest conidia, while isolates obtained from strawberry leaves had the shortest conidia. Meanwhile, conidia of isolates obtained from tea leaves were the widest, and those from walnut fruits were the narrowest. The length/width ratios of conidia in isolates from walnut fruits were higher than that of other hosts. In terms of appressoria, isolates from tea leaves had the longest appressoria, but those from walnut fruits of group 1 were the shortest. Similarly, appressoria of isolates from tea leaves were the widest, and appressoria of isolates from walnut fruits of group 1 were the narrowest. However, the length/width ratios of appressoria of isolates collected from walnut fruits were lower than those of other hosts, with a numerical value close to one.

Multilocus phylogenetic analyses. Twenty-four representative isolates collected from four different host plants and twenty-four previously characterized reference strains were analyzed by multilocus phylogenetic analyses (Table 2). Multilocus phylogenetic analysis was carried out by combining ITS, GADPH, ACT, TUB2, CAL, CHS-1, and HIS3 sequences with Colletotrichum guajavae (IMI 350839) as the outgroup taxa (Fig. 2). The dataset was composed of 3,285 characters including the alignment gaps. The topologies of phylogenetic trees were structured with the ML and NJ methods and were basically concordant with each other, manifesting that the evolutionary relationship of the test strains was statistically supported. The phylogenetic tree showed that the 24 representative isolates belonged to five distinct clades. The isolates obtained from grape fruits clustered with $C$. gloeosporioides s.s., while those from tea leaves clustered with $C$. camelliae. Four strains from strawberry leaves corresponded to $C$. fructicola. The strains HTTJ1 and HTTJ3 created a separate branch with a $99 \%$ bootstrap value (NJ) and was a sister taxon to $C$. acutatum s.s. Furthermore, three strains from

Table 3. Mean conidium and appressoria of length, width, and length/width ratio among isolates from different hosts ${ }^{\mathrm{a}}$

\begin{tabular}{|c|c|c|c|c|c|c|c|c|}
\hline \multirow[b]{2}{*}{ Isolates $^{\mathbf{b}}$} & \multirow[b]{2}{*}{ Host } & \multirow[b]{2}{*}{ Morphological group } & \multicolumn{3}{|c|}{ Conidial } & \multicolumn{3}{|c|}{ Appressoria } \\
\hline & & & Length $(\mu \mathrm{m})$ & Width $(\mu \mathrm{m})$ & Length/width ratio & Length $(\mu \mathrm{m})$ & Width $(\mu \mathrm{m})$ & Length/width ratio \\
\hline HTTJ1 & Walnut & Group 2 & $16.63(0.59)$ & $5.45(0.23)$ & $3.07(0.11)$ & $15.65(0.68)$ & $13.98(0.95)$ & $1.14(0.06)$ \\
\hline HTTJ3 & Walnut & Group 2 & $16.37(0.31)$ & $5.63(0.64)$ & $2.91(0.25)$ & $15.63(0.63)$ & $14.01(0.32)$ & $1.13(0.08)$ \\
\hline HTTJ6 & Walnut & Group 1 & $16.72(0.38)$ & $5.39(0.25)$ & $3.11(0.17)$ & $10.47(0.54)$ & $9.73(0.47)$ & $1.09(0.03)$ \\
\hline HTTJ12 & Walnut & Group 1 & $16.29(0.46)$ & $5.51(0.12)$ & $2.97(0.08)$ & $10.65(0.48)$ & $9.88(0.39)$ & $1.08(0.10)$ \\
\hline HTTJ15 & Walnut & Group 1 & $16.99(0.93)$ & $5.70(0.23)$ & $3.00(0.19)$ & $10.32(1.48)$ & $9.05(1.65)$ & $1.14(0.03)$ \\
\hline CMTJ1 & Strawberry & Group 3 & $14.30(0.58)$ & $5.86(0.26)$ & $2.44(0.11)$ & $24.15(0.75)$ & $17.63(0.34)$ & $1.37(0.02)$ \\
\hline CMTJ4 & Strawberry & Group 4 & $15.22(0.56)$ & $6.21(0.31)$ & $2.50(0.16)$ & $14.68(0.96)$ & $12.55(0.25)$ & $1.17(0.04)$ \\
\hline CMTJ7 & Strawberry & Group 3 & $14.56(0.39)$ & $5.88(0.21)$ & $2.48(0.26)$ & $23.48(0.36)$ & $18.03(0.37)$ & $1.30(0.32)$ \\
\hline CMTJ9 & Strawberry & Group 3 & $14.38(0.34)$ & $5.67(0.32)$ & $2.53(0.12)$ & $23.89(0.54)$ & $17.92(0.52)$ & $1.33(0.08)$ \\
\hline CMTJ13 & Strawberry & Group 4 & $15.45(0.36)$ & $6.56(0.52)$ & $2.36(0.23)$ & $15.38(0.34)$ & $12.56(0.53)$ & $1.23(0.17)$ \\
\hline CMTJ18 & Strawberry & Group 3 & $14.67(0.43)$ & $5.87(0.58)$ & $2.50(0.27)$ & $24.01(0.48)$ & $17.95(0.36)$ & $1.34(0.18)$ \\
\hline CMTJ21 & Strawberry & Group 4 & $15.31(0.73)$ & $6.12(0.39)$ & $2.50(0.37)$ & $15.81(0.37)$ & $13.28(0.42)$ & $1.20(0.09)$ \\
\hline PTTJ1 & Grape & Group 5 & $16.93(1.61)$ & $6.39(0.83)$ & $2.65(0.25)$ & $19.74(0.72)$ & $13.90(1.34)$ & $1.42(0.74)$ \\
\hline PTTJ7 & Grape & Group 5 & $17.12(1.33)$ & $5.78(0.31)$ & $2.83(0.18)$ & $22.34(1.37)$ & $17.54(1.15)$ & $1.32(0.17)$ \\
\hline PTTJ11 & Grape & Group 5 & $17.07(1.73)$ & $6.33(0.21)$ & $2.72(0.22)$ & $18.57(0.46)$ & $14.97(0.63)$ & $1.26(0.08)$ \\
\hline PTTJ14 & Grape & Group 5 & $16.83(0.96)$ & $6.04(0.38)$ & $2.79(0.36)$ & $19.73(0.25)$ & $13.89(1.42)$ & $1.42(0.93)$ \\
\hline PTTJ22 & Grape & Group 5 & $17.20(1.76)$ & $6.72(0.73)$ & $2.56(0.37)$ & $19.35(0.36)$ & $13.92(0.36)$ & $1.39(0.56)$ \\
\hline PTTJ24 & Grape & Group 5 & $16.84(0.83)$ & $6.48(0.62)$ & $2.60(0.31)$ & $19.42(0.38)$ & $14.27(0.53)$ & $1.36(0.11)$ \\
\hline PTTJ38 & Grape & Group 5 & $16.86(0.72)$ & $6.59(0.54)$ & $2.56(0.16)$ & $18.83(0.51)$ & $13.92(0.62)$ & $1.36(0.32)$ \\
\hline CSTJ2 & Tea plant & Group 6 & $18.22(0.49)$ & $7.89(0.35)$ & $2.33(0.11)$ & $27.81(0.89)$ & $18.60(1.35)$ & $1.52(0.08)$ \\
\hline CSTJ8 & Tea plant & Group 6 & $18.33(0.58)$ & $7.38(0.74)$ & $2.48(0.16)$ & $29.72(0.48)$ & $18.46(1.04)$ & $1.61(0.82)$ \\
\hline CSTJ13 & Tea plant & Group 6 & $17.67(0.39)$ & $7.50(0.52)$ & $2.40(0.18)$ & $36.63(0.36)$ & $23.74(0.52)$ & $1.55(0.05)$ \\
\hline CSTJ20 & Tea plant & Group 6 & $18.47(0.56)$ & $7.63(0.37)$ & $2.42(0.35)$ & $28.67(0.83)$ & $18.36(0.72)$ & $1.56(0.34)$ \\
\hline CSTJ23 & Tea plant & Group 6 & $17.93(0.49)$ & $7.73(0.53)$ & $2.32(0.23)$ & $29.47(0.52)$ & $18.53(0.63)$ & $1.59(0.16)$ \\
\hline
\end{tabular}

${ }^{a}$ Numbers in parentheses represent standard error of the mean based on least square means $(P=0.05)$.

${ }^{\mathrm{b}}$ Isolates were selected as representative of each group and host plant. 
strawberry leaves and three strains from walnut fruits formed a clade with $C$. viniferum.

Pathogenicity tests. In addition to the isolates from walnut fruits, other representative isolates of Colletotrichum produced typical symptoms of anthracnose on detached leaves or fruits (Fig. 3). These tested Colletotrichum species collected from four hosts showed different infection incidences. C. fructicola isolates obtained from strawberry leaves were more virulent than $C$. viniferum isolates from strawberry leaves. Only $C$. fructicola isolates collected from strawberry leaves had sporulation abilities (data not shown). However, seven isolates collected from grape fruits showed no significant differences in lesion length and width $(P>0.05)$. There was no significant difference in toxicity among all $C$. camelliae strains to tea leaves. Two species from walnuts did not infect the walnut fruits; we considered that this was caused by the thicker epidermis of walnut fruits.

Sensitivity of Colletotrichum spp. to fungicides. The sensitivities of isolates from four different host plants to the fungicides were determined using the mycelial growth method (Table 4). No significant differences in sensitivities were observed among all tested isolates for the same fungicide $(P>0.05)$. The independent variables fungicide, species, and plant all generally had effects on the $\mathrm{EC}_{50}$ of six fungicides against mycelial growth of Colletotrichum spp. (Table 4). All of the six fungicides had high activity against

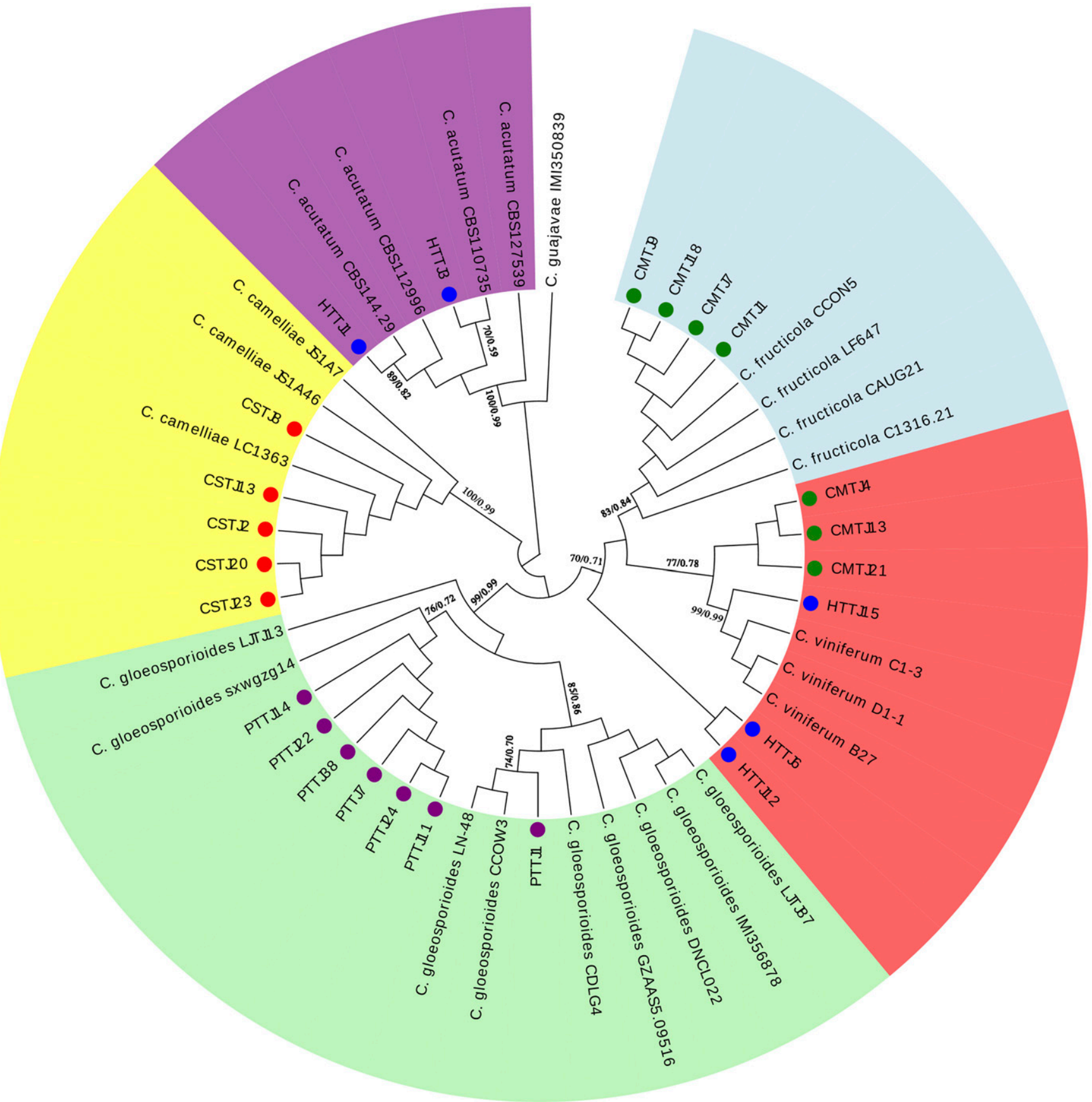

Fig. 2. Maximum likelihood (ML) consensus tree based on a 7-gene combined dataset (ITS, GAPDH, ACT, TUB2, CAL, CHS-1, HIS3) showing phylogenetic affinities of Colletotrichum isolates from different hosts in this study. Bootstrap support values (ML $\geq 50 \%$ ) and $\mathrm{NJ}$ bootstrap support values (NJ $\geq 50 \%)$ are displayed at the nodes (ML/NJ). Colletotrichum guajavae IMI 350839 was used as the out-group. Different background colors represent different species $(C$. gloeosporioides sensu stricto is covered with green, C. fructicola is covered with blue, C. camelliae is covered with yellow, C. viniferum is covered with red, C. acutatum sensu stricto is covered with purple.). The species of this study are marked with small round dots (Strains from grape fruits are marked with purple, strains from strawberry leaves are marked with green, strains from walnut fruits are marked with blue, strains from tea leaves are marked with red.). 
the mycelial growth of all isolates, with the highest $\mathrm{EC}_{50}$ values at $1.63 \mathrm{mg} / \mathrm{liter}$.

Based on all representative strains from the same plant, fludioxonil was the most effective against isolates from walnut fruits, difenoconazole was the most effective against isolates from strawberry leaves, and pyraclostrobin was the most effective against isolates from tea leaves (Table 4). The sensitivities of isolates from grape fruits to fungicides was inconsistent. The sensitivities of five isolates (C. camelliae) of tea leaves to six fungicides were similar, whereas the sensitivities of seven isolates (C. gloeosporioides s.s.) of grape fruits to fungicides were different (Table 4).

Based on isolates, the $\mathrm{EC}_{50}$ values of pyraclostrobin and tebuconazole against the mycelial growth of PTTJ7 were lower than those of any other fungicides in this study (mean $\mathrm{EC}_{50}=0.08,0.07 \mathrm{mg} / \mathrm{liter}$ )

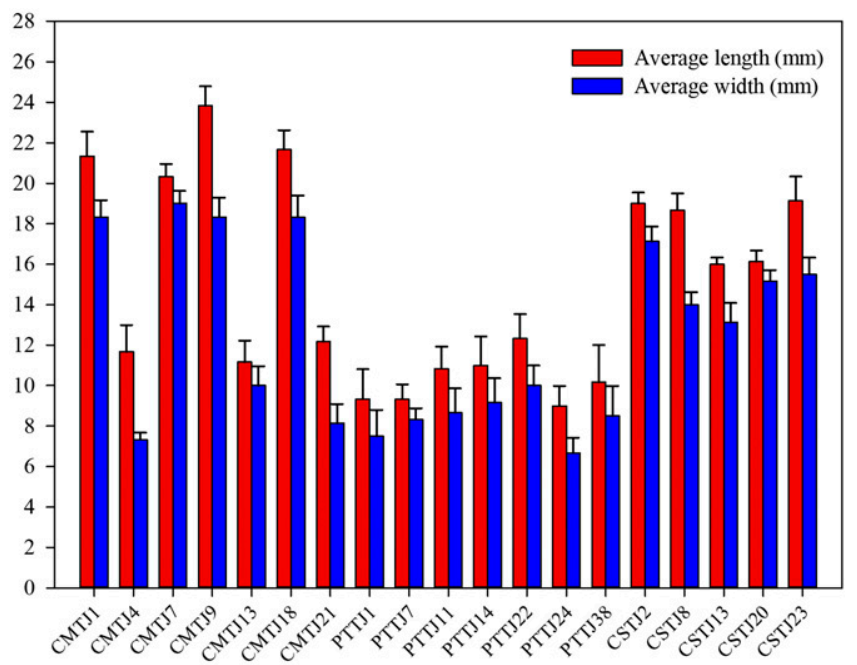

Isolates

Fig. 3. Average length and width represent disease severity of anthracnose caused by Colletotrichum spp. from different hosts. Values are mean and standard error (SE), with columns and bars indicating mean and SE.

Table 4. Mean half maximal effective concentration $\left(\mathrm{EC}_{50}\right)$ values of mycelial growth of Colletotrichum spp. from four hosts to six fungicides ${ }^{\mathrm{a}}$

\begin{tabular}{|c|c|c|c|c|c|c|}
\hline \multirow[b]{2}{*}{ Isolate } & \multicolumn{6}{|c|}{$\mathbf{E C}_{50}(\mathrm{mg} / \mathrm{liter})$} \\
\hline & Pyrac & Difen & Fludi & Tebuc & Pyris & Tetra \\
\hline HTTJ1 & $0.43(0.11)$ & $0.45(0.18)$ & $0.21(0.10)$ & $0.58(0.13)$ & $0.41(0.19)$ & $0.30(0.12)$ \\
\hline НTTJ3 & $0.78(0.03)$ & $0.32(0.17)$ & $0.28(0.06)$ & $0.31(0.13)$ & $0.89(0.12)$ & $0.38(0.11)$ \\
\hline HTTJ6 & $0.54(0.10)$ & $0.44(0.12)$ & $0.25(0.09)$ & $0.56(0.06)$ & $0.45(0.07)$ & $0.33(0.07)$ \\
\hline HTTJ12 & $0.48(0.02)$ & $0.51(0.09)$ & $0.26(0.01)$ & $0.49(0.11)$ & $0.61(0.22)$ & $0.40(0.08)$ \\
\hline HTTJ15 & $0.89(0.33)$ & $0.25(0.10)$ & $0.22(0.02)$ & $0.24(0.09)$ & $0.97(0.21)$ & $0.23(0.03)$ \\
\hline CMTJ1 & $0.26(0.09)$ & $0.16(0.08)$ & $0.30(0.12)$ & $0.39(0.17)$ & $0.39(0.13)$ & $0.17(0.07)$ \\
\hline CMTJ4 & $0.67(0.17)$ & $0.08(0.01)$ & $0.40(0.13)$ & $0.36(0.12)$ & $0.53(0.17)$ & $0.41(0.13)$ \\
\hline CMTJ7 & $0.32(0.03)$ & $0.19(0.08)$ & $0.44(0.11)$ & $0.38(0.04)$ & $0.58(0.10)$ & $0.29(0.01)$ \\
\hline CMTJ9 & $0.42(0.07)$ & $0.11(0.02)$ & $0.38(0.06)$ & $0.41(0.02)$ & $0.55(0.08)$ & $0.30(0.09)$ \\
\hline CMTJ13 & $0.59(0.12)$ & $0.15(0.01)$ & $0.37(0.07)$ & $0.45(0.02)$ & $0.47(0.01)$ & $0.42(0.11)$ \\
\hline CMTJ18 & $0.37(0.03)$ & $0.20(0.04)$ & $0.47(0.10)$ & $0.48(0.11)$ & $0.38(0.02)$ & $0.33(0.05)$ \\
\hline CMTJ21 & $0.38(0.07)$ & $0.23(0.03)$ & $0.52(0.16)$ & $0.39(0.11)$ & $0.48(0.05)$ & $0.26(0.07)$ \\
\hline PTTJ1 & $0.24(0.03)$ & $0.18(0.03)$ & $0.26(0.06)$ & $0.86(0.33)$ & $1.48(0.45)$ & $0.08(0.03)$ \\
\hline PTTJ7 & $0.08(0.01)$ & $0.35(0.21)$ & $0.15(0.04)$ & $0.07(0.02)$ & $0.86(0.32)$ & $0.26(0.11)$ \\
\hline PTTJ11 & $0.21(0.06)$ & $0.48(0.16)$ & $0.14(0.08)$ & $0.38(0.17)$ & $1.63(0.43)$ & $1.32(0.55)$ \\
\hline PTTJ14 & $0.52(0.18)$ & $0.20(0.09)$ & $0.86(0.34)$ & $0.33(0.18)$ & $0.33(0.18)$ & $0.12(0.03)$ \\
\hline РTTJ22 & $0.57(0.15)$ & $0.41(0.18)$ & $0.25(0.13)$ & $0.10(0.07)$ & $1.06(0.34)$ & $0.33(0.12)$ \\
\hline PTTJ24 & $0.25(0.08)$ & $0.38(0.09)$ & $0.19(0.03)$ & $0.38(0.08)$ & $1.00(0.23)$ & $0.83(0.22)$ \\
\hline PTTJ38 & $0.52(0.11)$ & $0.48(0.08)$ & $0.22(0.10)$ & $0.43(0.12)$ & $0.92(0.16)$ & $0.52(0.13)$ \\
\hline CSTJ2 & $0.28(0.09)$ & $0.35(0.14)$ & $1.21(0.32)$ & $0.51(0.13)$ & $0.73(0.24)$ & $0.29(0.09)$ \\
\hline CSTJ8 & $0.26(0.06)$ & $0.33(0.16)$ & $1.48(0.54)$ & $0.53(0.18)$ & $0.65(0.26)$ & $0.30(0.11)$ \\
\hline CSTJ13 & $0.29(0.08)$ & $0.31(0.03)$ & $1.50(0.44)$ & $0.55(0.24)$ & $0.69(0.28)$ & $0.31(0.15)$ \\
\hline CSTJ20 & $0.26(0.05)$ & $0.36(0.17)$ & $1.38(0.54)$ & $0.58(0.33)$ & $0.74(0.23)$ & $0.31(0.09)$ \\
\hline CSTJ23 & $0.27(0.03)$ & $0.38(0.09)$ & $1.51(0.37)$ & $0.52(0.34)$ & $0.66(0.38)$ & $0.35(0.21)$ \\
\hline
\end{tabular}

a Fungicides pyraclostrobin (Pyrac), difenoconazole (Difen), fludioxonil (Fludi), tebuconazole (Tebuc), pyrisoxazole (Pyris), tetramycin (Tetra). Numbers in parentheses represent standard error of the mean based on least square means $(P=0.05)$.
(Table 4). Moreover, the $\mathrm{EC}_{50}$ values of pyrisoxazole and tetramycin against the mycelial growth of PTTJ11 were higher than those of any other isolates in the study (mean $\mathrm{EC}_{50}=1.63,1.32 \mathrm{mg} / \mathrm{liter}$ ) (Table 4).

Based on the mean $\mathrm{EC}_{50}$ value of the same host, the mean $\mathrm{EC}_{50}$ of the mycelial growth of Colletotrichum spp. from tea leaves against fludioxonil was higher than that of any other fungicides, and the mean $\mathrm{EC}_{50}$ of Colletotrichum spp. from strawberry leaves against difenoconazole was lower than that of other fungicides in this study (Fig. 4). High error lines indicated that the sensitivities of different strains from the same crop to fungicides are greatly different (Fig. 4). The fungicide (difenoconazole, tetramycin) sensitivity of mycelial growth among different hosts was, on average, significantly higher than the sensitivity to pyrisoxazole (Fig. 4).

Effect of temperature on mycelial growth. In this test, the mycelial growth of the representative isolates was significantly influenced by temperature alteration $(P<0.05)$ (Fig. 5). The optimal temperature for mycelial growth was found to be $25^{\circ} \mathrm{C}$ for the isolates collected from walnut fruits and tea leaves, but it was $28^{\circ} \mathrm{C}$ for the

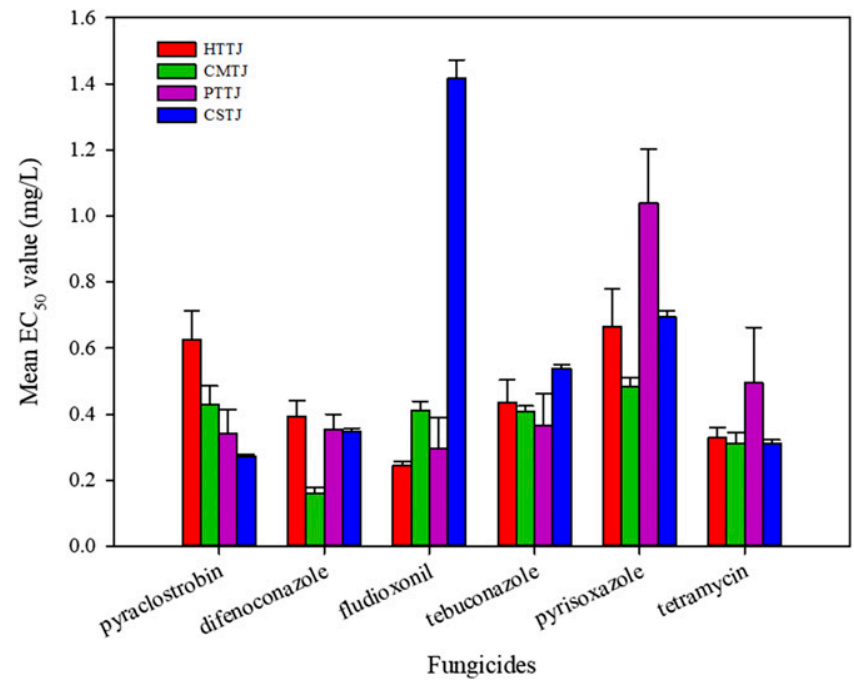

Fig. 4. Mean $E_{50}$ values of Colletotrichum spp. from four hosts to pyraclostrobin (Pyrac), difenoconazole (Difen), fludioxonil (Fludi), tebuconazole (Tebuc), pyrisoxazole (Pyris), tetramycin (Tetra). Comparison of sensitivity among different hosts. Values are mean and standard error (SE), with columns and bars indicating mean and SE.

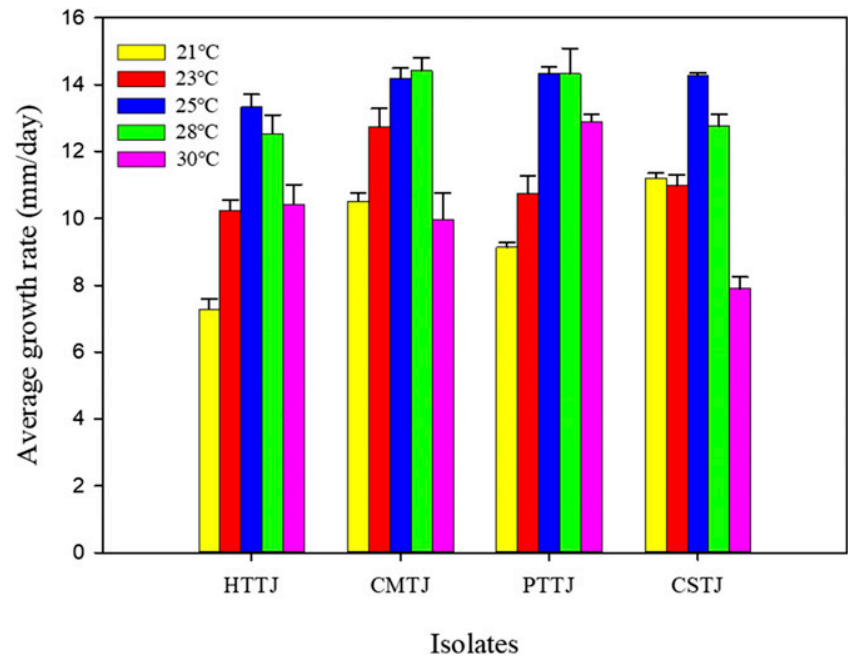

Fig. 5. Average growth rate of Colletotrichum species among different hosts at five selected temperatures. Values are mean and standard error (SE), with columns and bars indicating mean and SE. 
isolates collected from strawberry leaves and grape fruits (Fig. 5). The growth rate of strains from strawberry leaves and grape fruits at $25^{\circ} \mathrm{C}$ was not significantly different from that at $28^{\circ} \mathrm{C}(P>0.05)$ (Fig. 5). These results indicated that the optimal temperature for mycelial growth of isolates was $25-28^{\circ} \mathrm{C}$ regardless of the hosts that they were collected from (Fig. 5).

\section{Discussion}

Recent reports suggested that anthracnose affected a wide range of plants, and the species were complex (Damm et al. 2012a, b; Weir et al. 2012). This study aimed to compare and identify the Colletotrichum species isolated from different hosts in Shandong Province, China. According to the morphological characteristics and multilocus phylogenetic analyses, the 101 isolates were categorized into six groups, namely, group 1 (14 strains from walnut fruits, 13.9\%), group 2 (3 strains from walnut fruits, $2.9 \%$ ), group 3 (13 strains from strawberry leaves, $12.9 \%$ ), group 4 ( 8 strains from strawberry leaves, $8.0 \%$ ), group 5 (38 strains from grape fruits, $37.6 \%)$, group 6 (25 strains from tea leaves, $24.7 \%$ ).

Regarding Colletotrichum complexes, many morphologically similar species were reported in economic crops and ornamental plants (Hyde et al. 2009a, b). However, when morphological detection was conducted to classify the experimental isolates into six groups, seven Colletotrichum species were actually identified by multilocus phylogenetic analysis (Liu et al. 2016). Therefore, the identification of Colletotrichum species by morphological characteristics alone cannot be considered reliable. At present, the most powerful identification of Colletotrichum complexes was achieved by the incorporation of the morphological analysis and multilocus phylogeny (Crouch et al. 2006, 2009; Damm et al. 2012a, b; Guerber et al. 2003; Weir et al. 2012). In this study, the morphological groups based on colony characteristics, conidial morphology, and appressorium morphology were entirely in line with the results of the multilocus phylogenetic analysis deduced from the molecular data. Furthermore, either the maximum likelihood (ML) or neighborjoining (NJ) analysis was sufficiently high to classify them into separate species.

The name Colletotrichum gloeosporioides s.s. was the first to be applied to Colletotrichum isolates connected with diseases of Citrus in Italy (Penzig 1882). C. gloeosporioides s.s., a biologically and genetically diverse species, threatened at least 470 different host genera (Sutton 1980). C. gloeosporioides s.s. was previously reported to infect many mature fruits, particularly in the tropical zone (Freeman et al. 1998; Lin et al. 2016; Sangeetha and Rawal 2008). In recent years, Colletotrichum species were increasingly prevalent in the temperate monsoon climate zone, e.g., the Shandong, Hebei, and Shanxi provinces in China (Jayawardena et al. 2016; Zhu et al. 2014). Our research showed that all of the strains collected from grapes formed the same clade of $C$. gloeosporioides s.s. C. fructicola, a non-hostspecific pathogen, threatens a wide range of hosts (Liu et al. 2016; Weir et al. 2012) and belongs to C. gloeosporioides sensu lato. It has been reported to cause strawberry anthracnose in China, Canada, and the United States (Jayawardena et al. 2016; Weir et al. 2012). In the current study, 13 of 101 isolates obtained from strawberry leaves were described as $C$. fructicola based on morphological characteristics and multigene phylogenetic analysis.

C. acutatum s.s. is widely reported to infect walnuts (Liu et al. 1995), strawberries (Than et al. 2008), apples (Víchová et al. 2012), peppers (Harp et al. 2014), and grapes (Samuelian et al. 2014). In our study, the three strains isolated from Jinan, Shandong Province, China, were identified as $C$. acutatum s.s., whose colony, conidia, and appressoria morphology were obviously different from those of the other strains. Their genetic relationship was more distant than those of other strains. As far as we know, the earliest record of anthracnose was described from living leaves of tea (Willis et al. 1899). C. camelliae is still widely listed as the causal agent of the anthracnose of tea plants. (Liu et al. 2015) and (Weir et al. 2012) reported that $C$. camelliae was found in samples of tea anthracnose in different provinces in China. In our research, five representative strains obtained from tea leaves formed a separate clade with $C$. camelliae in the phylogenetic tree. Morphological characteristics of the isolates collected from tea leaves were consistent with those reported by Liu et al. (2015). Pathogenic species associated with strawberry anthracnose are very extensive, including $C$. coccodes (Cannon et al. 2012), C. cuscutae (Damm et al. 2012a), C. fioriniae (Damm et al. 2012a), C. fructicola (Weir et al. 2012), C. godetiae (Damm et al. 2012a), C. nymphaeae (Damm et al. 2012a), C. salicis (Damm et al. 2012a), and C. simmondsii (Damm et al. 2012a). This article was the first report of $C$. viniferum causing strawberry anthracnose in Shandong Province, China. C. viniferum had formerly been isolated from pathogenic sites of grapes in China (Peng et al. 2013; Yan et al. 2015). Likewise, our research was the first to identify the anthracnose of walnuts caused by $C$. viniferum in Shandong Province, China, which indicates that $C$. viniferum has an extensive host range.

In this study, isolates obtained from different hosts were inoculated on detached leaves or fruits. Different Colletotrichum species revealed various degrees of pathogenicity by artificial inoculation on leaves or fruits. According to current data, the virulence of $C$. fructicola isolates collected from strawberry leaves toward strawberry leaves was significantly different from that of $C$. viniferum isolates. More importantly, isolates of $C$. fructicola from strawberry leaves were more aggressive than those of $C$. viniferum. Nevertheless, isolates of $C$. fructicola produced a large number of spores on strawberry leaves. Interestingly, $C$. viniferum isolates had no sign of spore production.

For growers, an effective and durable management strategy for controlling fungal diseases relies on timed applications of fungicides that have different modes of action. This research determined the sensitivity of Colletotrichum complex species to fungicides with different modes of action, such as pyraclostrobin, difenoconazole, fludioxonil, tebuconazole, pyrisoxazole, and tetramycin. Isolates from different hosts of the five Colletotrichum spp. revealed $\mathrm{EC}_{50}$ values of 0.07 to $1.63 \mathrm{mg} / \mathrm{liter}$ for all the fungicides. Although the $\mathrm{EC}_{50}$ values were relatively low, there was a slight difference between species. In previous studies, the $C$. acutatum species were more tolerant to fungicides compared with the $C$. gloeosporioides species (Greer et al. 2011; Jayasinghe and Fernando 1998; Munir et al. 2016). This phenomenon was not observed in this study. To better understand the species, further experiments need to be done in the future. Additionally, the $\mathrm{EC}_{50}$ values measured in this study are low, and fungicides may produce better control efficacy against Colletotrichum spp. in the field. Nevertheless, more field studies are needed in the future.

The effect of temperature on the growth rate of Colletotrichum spp. in vitro was also evaluated. The results showed that colony growth is the fastest in the temperature range of $25-28^{\circ} \mathrm{C}$. Prior to this study, the maximum growth rate occurred in the range of $25-30^{\circ} \mathrm{C}$ for Colletotrichum spp. isolates (Munir et al. 2016; Xu et al. 2017). Temperature plays an indispensable role in the infection process of anthracnose. Chongo and Bernier (2000) confirmed that the number of lesions and disease severity of anthracnose on lentils increased with temperature, reaching the highest damage at a temperature of $28^{\circ} \mathrm{C}$. Once the optimum growth temperature for the pathogen is reached, anthracnose may frequently occur, and thus this is the time to apply fungicides.

In the present study, we investigated the dissimilarity of Colletotrichum species obtained from four hosts in Shandong Province, China. Isolates of each host had only one or two species to be identified. The limited sample numbers and the limited host scope of the species investigated may be the main factors. Future work will be required to probe species collected from different geographical regions and the pathogenicity of Colletotrichum species reported on multiple hosts. This research is the first to report molecular and phenotypic characterization and fungicide sensitivity differences among species of different hosts from representative orchards in Shandong Province, China. According to the current data, we found that C. viniferum was a new species on walnut fruits and strawberry leaves, and its sensitivity to fungicides was not significantly different from that of other species. Therefore, we deduce that the fungicides 
used in this paper can be extensively used to prevent anthracnose on various hosts.

\section{Literature Cited}

Biggs, A. R., and Miller, S. 2001. Relative susceptibility of selected apple cultivars to Colletotrichum acutatum. Plant Dis. 85:657-660.

Cai, L., Hyde, K. D., Taylor, P., Weir, B. S., Waller, J. M., and Abang, M. M. 2009. A polyphasic approach for studying Colletotrichum. Fungal Divers. 39: 183-204.

Cannon, P. F., Damm, U., Johnston, P. R., and Weir, B. S. 2012. Colletotrichumcurrent status and future directions. Stud. Mycol. 73:181-213.

Carbone, I., and Kohn, L. M. 1999. A method for designing primer sets for speciation studies in Filamentous Ascomycetes. Mycologia 91:553-556.

Chen, Z. M., and Yang, Y. J. 2011. The classic of tea in China. Shanghai Culture Press 390.

Chongo, G., and Bernier, C. C. 2000. Effects of host, inoculum concentration, wetness duration, growth stage, and temperature on anthracnose of lentil. Plant Dis. 84:544-548.

Crouch, J. A., Clarke, B. B., and Hillman, B. I. 2006. Unraveling evolutionary relationships among the divergent lineages of Colletotrichum causing anthracnose in turfgrass and corn. Phytopathology 96:46-60.

Crouch, J. A., Tredway, L. P., Clarke, B. B., and Hillman, B. I. 2009. Phylogenetic and population genetic divergence correspond with habitat for the pathogen Colletotrichum cereale and allied taxa across diverse grass communities. Mol. Ecol. 18:123-135

Crous, P. W., Groenewald, J. Z., Risède, J. M., Simoneau, P., and Hyweljones, N. L. 2004. Calonectria species and their Cylindrocladium anamorphs: Species with sphaeropedunculate vesicles. Stud. Mycol. 18:415-430.

Damm, U., Cannon, P. F., Woudenberg, J. H. C., and Crous, P. W. 2012a. The Colletotrichum acutatum species complex. Stud. Mycol. 73:37-113.

Damm, U., Cannon, P. F., Woudenberg, J. H. C., Johnston, P. R., Weir, B. S., Tan, Y. P., Shivas, R. G., and Crous, P. W. 2012b. The Colletotrichum boninense species complex. Stud. Mycol. 73:1-36.

Diao, Y. Z., Zhang, C., Liu, F., Wang, W. Z., Liu, L., Cai, L., and Liu, X. L. 2017. Colletotrichum species causing anthracnose disease of chili in China. Persoonia Mol. Phylogeny Evol. Fungi 38:20-37.

Du, M., Schardl, C. L., Nuckles, E. M., and Vaillancourt, L. J. 2005. Using matingtype gene sequences for improved phylogenetic resolution of Colletotrichum species complexes. Mycologia 97:641-658.

Edgar, R. C. 2004. MUSCLE: Multiple sequence alignment with high accuracy and high throughput. Nucleic Acids Res. 32:1792-1797.

Freeman, S., Katan, T., and Shabi, E. 1998. Characterization of Colletotrichum species responsible for anthracnose diseases of various fruits. Plant Dis. 82: 596-605.

Gardes, M., and Bruns, T. D. 1993. ITS primers with enhanced specificity for basidiomycetes - application to the identification of mycorrhizae and rusts. Mol. Ecol. 2:113-118.

Glass, N. L., and Donaldson, G. C. 1995. Development of primer sets designed for use with the PCR to amplify conserved genes from Filamentous Ascomycetes. Appl. Environ. Microbiol. 61:1323-1330.

Greer, L. A., Harper, J. D. I., Savocchia, S., Samuelian, S. K., and Steel, C. C. 2011. Ripe rot of south-eastern Australian wine grapes is caused by two species of Colletotrichum: $C$. acutatum and $C$. gloeosporioides with differences in infection and fungicide sensitivity. Aust. J. Grape Wine Res. 17:123-128.

Guerber, J. C., Liu, B., Correll, J., and Johnston, P. R. 2003. Characterization of diversity in Colletotrichum acutatum sensu lato by sequence analysis of two gene introns, mtDNA and intron RFLPs, and mating compatibility. Mycologia 95:872-895.

Guo, M., Pan, Y., Dai, Y., and Gao, Z. 2014. First report of brown blight disease caused by Colletotrichum gloeosporioides on Camellia sinensis in Anhui Province, China. Plant Dis. 98:284.

Harp, T., Kuhn, P., Roberts, P. D., and Pernezny, K. L. 2014. Management and cross-infectivity potential of Colletotrichum acutatum, causing anthracnose on bell pepper in Florida. Phytoparasitica 42:31-39.

Hong, S. K., Kim, W. G., Yun, H. K., and Choi, K. J. 2008. Morphological variation, genetic diversity and pathogenicity of Colletotrichum species causing grape ripe rot in Korea. J. Plant Pathol. 24:269-278.

Hu, M., Grabke, A., Dowling, M. E., Holstein, H., and Schnabel, G. 2015. Resistance in Colletotrichum siamense from peach and blueberry to thiophanate-methyl and azoxystrobin. Plant Dis. 99:806-814

Hyde, K. D., Cai, L., Cannon, P. F., Crouch, J. A., Crous, P. W., Damm, U., et al. 2009a. Colletotrichum - names in current use. Fungal Divers. 39: 147-182.

Hyde, K. D., Cai, L., Ehc, M. K., Yang, Y. L., Zhang, J. Z., and Prihastuti, H. 2009b. Colletotrichum: A catalogue of confusion. Fungal Divers. 39:1-17.

Hyde, K. D., Nilsson, R. H., Alias, S. A., Ariyawansa, H. A., Blair, J. E., Cai, L., et al. 2014. One stop shop: backbones trees for important phytopathogenic genera: I (2014). Fungal Divers. 67:21-125

Jayasinghe, C. K., and Fernando, T. H. 1998. Growth at different temperatures and on fungicide amended media: Two characteristics to distinguish Colletotrichum species pathogenic to rubber. Mycopathologia 143:93-95.
Jayawardena, R. S., Huang, J., Jin, B., Yan, J., Li, X., Hyde, K., Bahkali, A., Yin, S., and Zhang, G. 2016. An account of Colletotrichum species associated with strawberry anthracnose in China based on morphology and molecular data. Mycosphere 7:1147-1163.

Johnston, P. R., and Jones, D. 1997. Relationships among Colletotrichum isolates from fruit-rots assessed using rDNA sequences. Mycologia 89:420-430.

Lin, T., Xu, X. F., Dai, D. J., Shi, H. J., Wang, H. D., and Zhang, C. Q. 2016 Differentiation in development of benzimidazole resistance in Colletotrichum gloeosporioides complex populations from strawberry and grape hosts. Australas. Plant Pathol. 45:241-249.

Liu, F., Tang, G., Zheng, X., Li, Y., Sun, X., Qi, X., Zhou, Y., Xu, J., Chen, H., Chang, X., Zhang, S., and Gong, G. 2016. Molecular and phenotypic characterization of Colletotrichum species associated with anthracnose disease in peppers from Sichuan Province, China. Sci. Rep. 6:32761.

Liu, F., Weir, B. S., Damm, U., Crous, P. W., Wang, Y., Liu, B., Wang, M., Zhang, M., and Cai, L. 2015. Unravelling Colletotrichum species associated with Camellia: Employing ApMat and GS loci to resolve species in the $C$. gloeosporioides complex. Persoonia Mol. Phylog. Evol. Fungi 35:63-86.

Liu, X. 2013. Studies on occurrence regularity and chemical control of walnut anthracnose. M.S. thesis. Tai' an: Shandong Agriculture University.

Liu, X., Jing, Y., and Yang, J. 1995. A study on Colletotrichum classification of wooden plant in Shaanxi Province.J. Northwest Fores. Coll. 10:29-30.

Lu, X. L. 2005. Studies on biochemistry and molecular biology of genetic diversity of grape cultivar and resistant appraisal of downy mildew. Ph.D. thesis. Sichuan Agricultural University, Sichuan.

Mcgranahan, G. H., Hansen, J., and Shaw, D. V. 1988. Inter- and intraspecific variation in California black walnuts. J. Am. Soc. Hortic. Sci. 83:210-215.

Munir, M., Amsden, B., Dixon, E., Vaillancourt, L., and Gauthier, N. A. W. 2016. Characterization of Colletotrichum species causing bitter rot of apples in Kentucky orchards. Plant Dis. 100:2194-2203.

Nilsson, R. H., Hyde, K. D., Pawłowska, J., Ryberg, M., Tedersoo, L., Aas, A. B. et al. 2014. Improving its sequence data for identification of plant pathogenic fungi. Fungal Divers. 67:11-19.

O'Donnell, K., and Cigelnik, E. 1997. Two divergent intragenomic rDNA ITS2 types within a monophyletic lineage of the fungus Fusarium are nonorthologous. Mol. Phylogenet. Evol. 7:103-116.

O’Donnell, K., Nirenberg, H. I., Aoki, T., and Cigelnik, E. 2000. A multigene phylogeny of the Gibberella fujikuroi species complex: Detection of additional phylogenetically distinct species. Mycoscience 41:61-78.

Peng, L. J., Sun, T., Yang, Y. L., Cai, L., Hyde, K. D., Bahkali, A. H., and Liu, Z. Y. 2013. Colletotrichum species on grape in Guizhou and Yunnan provinces, China. Mycoscience 54:29-41.

Penzig, A. G. O. 1882. Funghi agrumicoli. Contribuzione allo studio dei funghi parassiti degli agrumi. Michelia 2:385-408.

Peres, N. A. R., Souza, N. L., Peever, T. L., and Timmer, L. W. 2004. Benomyl sensitivity of isolates of Colletotrichum acutatum and C. gloeosporioides from citrus. Plant Dis. 88:125-130.

Qu, W. W., Yang, K. Q., Liu, H. X., and Wang, J. Y. 2011. Common diseases of walnut (Juglans regia L.) and the integrate management in Shandong Province. Plant Prot. 37:136-140.

Samuelian, S. K., Greer, L. A., Savocchia, S., and Steel, C. C. 2014. Application of Cabrio (a.i. pyraclostrobin) at flowering and veraison reduces the severity of bitter rot (Greeneria uvicola) and ripe rot (Colletotrichum acutatum) of grapes. Aust. J. Grape Wine Res. 20:292-298.

Sangeetha, C. G., and Rawal, R. D. 2008. Nutritional studies of Colletotrichum gloeosporioides (Penz.) Penz. and Sacc. the incitant of mango anthracnose. World J. Agric. Sci. 4:717-720.

Silva, D. D. D., Ades, P. K., Crous, P. W., and Taylor, P. W. J. 2016 Colletotrichum species associated with chili anthracnose in Australia. Plant Pathol. 66:1-14.

Silva, D. N., Talhinhas, P., Várzea, V., Cai, L., Paulo, O. S., and Batista, D. 2012. Application of the Apn2/MAT locus to improve the systematics of the Colletotrichum gloeosporioides complex: An example from coffee (Coffea spp.) hosts. Mycologia 104:396-409.

Smith, B. J. 2008. Epidemiology and pathology strawberry anthracnose: A North American perspective. HortScience 43:69-73.

Sutton, B. C. 1980. Page 696 in: The Coelomycetes. Fungi imperfecti with pycnidia, acervuli and stromata. Coelomycetes Fungi Imperfecti with Pycnidia Acervuli and Stromata. CMI, Kew, U.K.

Tamura, K., Stecher, G., Peterson, D., Filipski, A., and Kumar, S. 2013. MEGA6: Molecular evolutionary genetics analysis version 6.0. Mol. Biol. Evol. 30: 2725-2729.

Than, P. P., Jeewon, R., Hyde, K. D., Pongsupasamit, S., Mongkolporn, O., and Pwj, T. 2008. Characterization and pathogenicity of Colletotrichum species associated with anthracnose on chilli (Capsicum spp.) in Thailand. Plant Pathol. 57:562-572

Valero, M., García-Martínez, S., Giner, M. J., Alonso, A., and Ruiz, J. J. 2010 Benomyl sensitivity assays and species-specific PCR reactions highlight association of two Colletotrichum gloeosporioides types and C. acutatum with rumple disease on Primofiori lemons. Eur. J. Plant Pathol. 127:399-405.

Velho, A. C., Alaniz, S., Casanova, L., Mondino, P., and Stadnik, M. J. 2015. New insights into the characterization of Colletotrichum species associated with apple diseases in southern Brazil and Uruguay. Fungal Biol. 119:229-244. 
Víchová, J., Staňková, B., and PokornýR. 2012. First report of Colletotrichum acutatum on tomato and apple fruits in the Czech Republic. Plant Dis. 96: 769-770.

Weir, B. S., Johnston, P. R., and Damm, U. 2012. The Colletotrichum gloeosporioides species complex. Stud. Mycol. 73:115-180.

White, T. J., Bruns, T., Lee, S., and Taylor, J. 1990. Amplification and direct sequencing of fungal ribosomal RNA genes for phylogenetics. Pages 315-322 in: PCR protocols: A guide to methods and applications. M. A. Innis, D. H. Gelfand, J. J. Sninsky, and T. J. White, eds. Academic Press, New York.

Willis, J. C., M. A., and F. L. S. 1899. DCLII - Tea and coffee diseases. Bull. Miscellaneous Inf. R. Bot. Gardens, Kew 1899:89-94.

Xie, L., Zhang, J. Z., Wan, Y., and Hu, D. W. 2010. Identification of Colletotrichum spp. isolated from strawberry in Zhejiang Province and Shanghai City, China.
Journal of Zhejiang University-SCIENCE B (Biomedicine \& Biotechnology) 11:61-70.

$\mathrm{Xu}$, S., Christensen, M. J., and Li, Y. 2017. Pathogenicity and characterization of Colletotrichum lentis: A causal agent of anthracnose in common vetch (Vicia sativa). Eur. J. Plant Pathol. 2017:1-13.

Yan, J. Y., Jayawardena, M. M. R. S., Goonasekara, I. D., Wang, Y., Zhang, W., Liu, M., Huang, J. B., Wang, Z. Y., Shang, Y. L., Peng, Y. L., Bahkali, A., Hyde, K. D., and Li, X. H. 2015. Diverse species of Colletotrichum associated with grapevine anthracnose in China. Fungal Divers. 71:233246.

Zhu, Y. F., Yin, Y. F., Qu, W. W., and Yang, K. Q. 2014. Morphological and molecular identification of Colletotrichum gloeosporioides causing walnut anthracnose in Shandong Province, China. Acta Hortic.: 353-360. 